\title{
BAHASA SUNDA DIALEK TASIKMALAYA DI KECAMATAN KARANGNUNGGAL
}

\author{
Enur Sri Mulyani \\ MGMP Kabupaten Tasikmalaya \\ pos-el: enursri@yahoo.com
}

\begin{abstract}
Abstrak
Penelitian ini dilatarbelakangi oleh tergesernya bahasa Sunda dialek Tasikmalaya di Kecamatan Karangnunggal oleh bahasa asing karena adanya globalisasi dan kemajuan teknologi. Adapun tujuan dari penelitian ini adalah untuk mendeskripsikan tentang (1) Bahasa Sunda dialek Tasikmalaya, (2) ciri-ciri pembeda Bahasa Sunda dialek Tasikmalaya dengan Bahasa Sunda Lulugu, (3) bentuk kata Bahasa Sunda dialek Tasikmalaya, dan (4) dialektometri Bahasa Sunda dialek Tasikmalaya. Metode yang digunakan dalam penelitian ini adalah metode deskriptif dengan teknik wawancara, simak, dan observasi. Instumen yang digunakan dalam penelitian ini adalah kuisioner, daftar pertanyaan, dan alat rekam. Adapun hasil dari penelitian ini yaitu: pertama, ada 486 kosa kata bahasa Sunda dialek Tasikmalaya; kedua, terdapat 46 kata yang termasuk dalam pembeda fonetik, 7 kata termasuk pembeda morfologis, 6 kata termasuk pembeda homonimi, 411 termasuk pembeda sinonimi, 22 kata termasuk pembeda onomasiolgis, dan 15 kata termasuk pembeda semasiologis; ketiga, terdapat 324 kecap salancar yang ada pada empat pola suku kata, kata terbanyak ada pada pola dua suku kata, 137 kecap jembar yang terdiri dari 54 kecap rundayan, 28 kecap rajékan, 46 kecap kantétan, dan 9 kecap wancahan; keempat, hasil presentase dalektometri Bahasa Sudna dialek Tasikmalaya yaitu 55,39 yang artinya ada pada tingkat beda dialek. Bahasa Sunda dialék Tasikmalaya sudah sepatutnya dilestarikan oleh masyarakat khususnya masyarakat Kabupaten Tasikmalaya di Kecamatan Karangnunggal.
\end{abstract}

Kata Kunci: bahasa Sunda, dialek, Tasikmalaya.

\section{SUNDANESE DIALECT IN TASIKMALAYA IN KARANGNUNGGAL SUBDISTRICT}

\begin{abstract}
This research was motivated by the shift of Sundanese dialect in Tasikmalaya, particularly in Karangnunggal Subdistrict, due to foreign language campaign as the result of globalization and technological advancement. The purpose of this research was to describe about (1) Sundanese dialect Tasikmalaya, (2) the distinguishing features of Sundanese dialect Tasikmalaya with Sundanese Lulugu, (3) wangun kecap Sundanese dialect Tasikmalaya, and (4) dialectometry Sundanese dialect of Tasikmalaya. The method used in this research wass descriptive method with interview technique, references, and observation. The instruments used in this study were questionnaires, interview guides, and recording tools. The results of this study were; first, there were 486 Sundanese soy sauce in Tasikmalaya dialect; second, there were 46 words that belong to phonetic differentiator, 7 words including morphological differentiator, 6 words including homonymous differentiation, 411 including synonymous differentiation, 22 words including onomasiologis differentiator, and 15 words including semasiologic differentiator; third, there were 324 kecap salancar available in four syllabic patterns, most said in the two syllabic pattern, 137 kecap jembar consisting of 54 kecap rundayan, 28 kecap rajékan, 46 kecap kantétan, and 9 kecap wancahan; fourth, the result of dialectometry presentation of Tasikmalaya's dialect was 55,39 which means there is a different dialect level. Sundanese
\end{abstract}


dialect in Tasikmalaya was duly preserved by the community, especially Tasikmalaya regency in Karangnunggal subdistrict.

Key words: sundanese, dialect, Tasikmalaya.

\section{PENDAHULUAN}

Bahasa merupakan salah satu alat komunikasi yang dipakai manusia. Suatu bahasa lahir bersamaan dengan lahirnya manusia ke alam dunia. Begitupun bahasa Sunda, lahir bersamaan dengan lahirnya orang Sunda ke dunia. Di Indonesia, terdapat ratusan bahasa daerah dari Sabang sampai Merauke, dan salah satunya adalah bahasa Sunda. Menurut Sugiyono (2012), dari 726 bahasa daerah di Indonésia, ada tiga bahasa daerah yang paling banyak digunakan, yaitu bahasa Jawa, bahasa Sunda, dan bahasa Madura, jumlah penutur bahasa Sunda ada 34 juta jiwa.

Sebagai bahasa daerah di Indonesia, bahasa Sunda digunakan di Jawa Barat. Walaupun demikian, di daerah lain seperti di Lampung, ada sebagian yang menggunakan bahasa Sunda. Hal ini disebabkan oleh adanya transmigrasi orang Sunda ke daerah itu yang mengakibatkan bahasa Sunda tersebar di daerah itu.

Digunakannya bahasa Sunda tersebar di setiap daerah yang secara administrative ada pada cakupan pemerintahan kabupaten/ kota, terdapat juga dalam cakupan yang lebih kecil seperti kecamatan-kecamatan. Karena hidupnya bahasa Sunda ada pada macammacam latar daerah, bahasa Sunda mempunyai ragam atau variasi yang selaras dengan latar daerah itu sendiri. Ragam bahasa yang dipakai di daerah masing-masing disebut dialek. Walaupun demikian, ada yang disebut bahasa Sunda lulugu (standar) yang dimengerti oleh masyarakat Sunda di Jawa Barat. Sesuai dengan kedudukan kota Bandung sebagai pusat pemerintahan, yang artinya sebagai pusat kegiatan budaya sunda, maka bahasa Sunda Bandung dianggap sebagai bahasa lulugu (standar). Hal ini sesuai dengan pendapat Sudaryat, dkk. (2013, hal. 1) yang menjelaskan bahwa bahasa sekolah berubah menjadi bahasa lulugu yang mengakibatkan bahasa Sunda Bandung juga berubah menjadi bahasa lulugu (standar).

Selain dialék, setiap penutur mempunyai ragam bahasa khasnya sendiri yang disebut idiolek. Hal ini sesuai dengan pendapat Chaer (2010, hal. 63) yang menjelaskan bahwa para penutur dalam suatu dialek, meskipun mereka memiliki idioleknya masing-masing, memiliki kesamaan ciri yang menandai bahwa mereka berada pada satu dialek, yang berbeda dengan kelompok penutur lain, yang berada dalam dialeknya sendiri dengan ciri lain yang menandai dialeknya juga. Contohnya, masyarakat Tasikmalaya di Kecamatan Karangnunggal mempunyai kata "kompodan" yang artinya sama dengan kata "borangan" dalam bahasa Sunda lulugu. Kata "kompodan" dianggap lumrah dan dimengerti oleh masyarakat Tasikmalaya di Kecamatan Karangnunggal. Tapi, akan beda halnya jika kata itu digunakan di daerah lain. Bisa jadi berbeda arti atau mungkin tidak mengenal kata "kompodan". Hal itu menunjukan bahwa bahasa Sunda dialek Tasikmalaya di Kacamatan Karangnunggal mempunyai ciri yag berbeda dengan bahasa Sunda daerah lain seperti Ciamis, Kuningan, Bandung, dsb.

Jumlah kata dalam bahasa Sunda dialek tentu banyak. Akan tetapi, seiring dengan berjalnnya waktu, kosa kata itu bukannya bertambah tapi malah semakin berkurang apalagi di kalangan remaja. Hal ini disebabkan masuknya bahasa-bahasa kosta yang dipakai oleh kalangan remaja 
karena adanya globalisasai dan kemajuan teknologi.

Kemajuan teknologi telah menyebabkan masuknya bahasa-bahasa asing melalui televisi, radio, atau handphone. Hal itu menyebabkan masuknya bahasa-bahasa asing (bahasa Indonesia dan bahasa Inggris) yang tidak bisa diterjemahkan ke dalam bahasa Sunda, tetapi tetap dipaksakan untuk dipakai. Jadi, agar bahasa Sunda dialek Tasikmalaya di Kecamatan Karangnunggal tidak punah karena tergerus oleh kemajuan teknologi, perlu adanya penelitian dan inventarisasi supaya bahasa Sunda dialek Tasikmalaya di Kecamatan Karangnunggal bisa dipakai kembali oleh masyarakat.

Berkaca pada penelitian sebelumnya, memang sudah banyak penelitian tentang bahasa Sunda dialek di Jawa Barat. Khususnya penelitian yang dilaksanakan oleh Departemen Pendidikan Bahasa Daerah, di antaranya yaitu "Basa Sunda Dialék Bekasi di Kacamatan Setu pikeun Bahan Pangajaran Maca di SMA" (Murdiani, 2013). Dalam penelitian ini, membahas bahasa Sunda dialek Bekasi mulai dari kosa kata, persentase istilah, dialektometri, dan peta sebaran. Perbedaan dengan penelitian ini adalah tidak dibahasnya persentase istilah dan tidak dihubungkan dengan pengajaran.

Ada juga penelitian tentang "Basa Sunda Dialék Parung Panjang nu dipaké ku Siswa SMP/SMA di Kacamatan Parung Panjang Kabupatén Bogor" (Marantika, 2016). Perbedaan signifikan dari penelitian ini adalah sumber penelitiannya. Sumber data dari peneltian sebelumnya adalah siswa SMP/ SMA yang ada di Parung Panjang, sedangkan dalam penelitian ini sumber data yang dipakai adalah masyarakat asli Kabupaten Tasikmalaya di Kecamatan Karangnunggal.

Selain itu, ada penelitian tentang "Geografi Basa Sunda Dialék Kabupatén Tasikmalaya" (Yudibrata, dkk. 1983).
Walaupun penelitian ini dilaksanakan di kabupaten yang sama, tetapi mempunyai perbedaan yang signifikan di antaranya, berlangsungnya penelitian dalam kurun waktu yang jauh kurang lebih tiga puluh empat tahun yang lalu. Selain dari itu, penelitian terdahulu meneliti dialek sekabupatén Tasikmalaya yang di dalamnya terdapat 25 kecamatan. Salah satu kecamatan yang ditelitinya adalah Kecamatan karangnunggal. Namun, dari 14 desa yang ada di Kecamatan Karangnunggal, hanya 2 desa yang diteliti. Berbeda dengan dengan penelitian sebelumnya, penelitian ini dilaksanakan dalam keadaan zaman yang sudah lebih maju dan kehidupan masyarakat yang lebih modern. Selain itu, cakupan wilayah penelitian ini berpusat di Kecamatan Karangnunggal.

Oleh karena itu, penelitian ini diberi judul "Basa Sunda Dialék Tasikmalaya di Kacamatan Karangnunggal" perlu dilaksanakan. Dari penelitian ini, diharapkan bisa memberikan pembahasan yang dalam mengenai bahasa Sunda dialek Tasikmalaya, khususnya di Kecamatan Karangnunggal serta bisa dijadikan pembeda ciri khas bahasa dialek yang dimiliki oleh masyarakat Tasikmalaya. Juga diharapkan bisa dijadikan inventarisasi untuk mengenal bahasa Sunda dialek Tasikmalaya di Kecamatan Karangnunggal dan menumbuhkan kembali rasa bangga terhadap bahasa Sunda di daerah penelitian.

\section{MÉTODE}

Dalam suatu penelitian diperlukan cara untuk mengumpulkan data penelitian yang disebut metode penelitian (Arikunto, 2013, hal. 203). Metode yang digunakan dalam penelitian ini adalah metode deskriptif. Metode ini digunakan untuk menggambarkan secara sistematik dan akurat. Metode ini menginterpretasikan objek berdasarkan kenyataan yang sebenarnya (Azwar, 2012, hal. 7); mendeskripsikan atau menjelaskan 
peristiwa dan kejadian yang ada (Sudjana, 2015, hal. 52).

Teknik yang digunakan dalam penelitian ini adalah wawancara, simak dan observasi. Adapun instrumen yang digunakan dalam penelitian ini adalah kuisioner, daptar tanyaan, dan alat rekam.

Teknik mengolah data yang digunakan dalam penelitian ini adalah metode padan. Artinya, suatu hal yang dibandingkan mempunyai makna dan hubungan. Oleh sebab itu, padan dalam konteks ini diartikan selaku hubunganbandingan (Mahsun dalam Widyastuti, 2017, hal. 102). Dalam penelitian ini, metode padan digunakan untuk menganalisis adanya perbedaan unsur kebahasaan bahasa Sunda dialek Tasikmalaya di Kecamatan Karangnunggal dan bahasa Sunda lulugu (standar).

Berdasarkan sifatnya, sumber penelitian dialek bisa dibagi dua bagian, yaitu sumber lisan dan sumber tulisan (Ayatrohaedi, 1979, hal. 11). Sumber lisan berkaitan dengan masih adanya bahasa atau dialek yang sampai sekarang belum terdapat dokumen-dokumen yang tertulis. Sumber lisan itu berupa bahasa atau dialek itu sendiri maupun hal-hal yang terkandung di dalamnya, seperti cerita rakyat, adat istiadat, kepercayaan, dan perundagian (Guiraud dalam Ayatrohaedi, 1979, hal. 11). Sementara itu, sumber tulisan memberikan bantuan di dalam usaha penelitian sumber lisan. Bahkan, kadang-kadang penelitian dialektologi hanya dapat dilakukan dengan menggunakan sumber tulis saja, seperti naskah-naskah kuno, kamus, atlas bahasa, dan dokumen-dokumen laind alam dialek yang diteliti (Zulaeha, 2010, hal. 52). Sumber data lisan dalam penelitian ini yaitu bahasa Sunda dialek Tasikmalaya di Kecamatan Karangnunggal.

Sumber data lisan dalam penelitian ini adalah informan. Informan yaitu seseorang yang memberi informasi tentang data yang sedang diteliti. Hal ini sejalan dengan pendapat Zulaeha (2010, hal. 53) yang menjelaskan bahwa informan adalah orang yang memberi informasi data basa dialek yang diteliti, atau yang disebut pembahan (Ayatrohaedi, 1979).

Dalam penelitian ini, informan penelitian dipilih berdasarkan kriteria:

a. berjenis kelamin laki-laki atau perempuan,

b. berusia \pm 30 s.d. \pm 60 tahun,

c. lahir dan besar di desa setempat,

d. dapat berbahasa sunda,

e. dapat berbahasa indonesia, dan

f. sehat rohani dan jasmani, dalam arti alat bicaranya sempurna (Zulaeha, 2010, hal. 54).

\section{HASIL DAN PEMBAHASAN \\ Bahasa Sunda Dialek Tasikmalaya di Kecamatan Karangnunggal}

Kata merupakan bagian kalimat paling kecil yang sifatnya bebas serta mengandung makna tertentu (Sudaryat, dkk. 2013, hal. 48). Contohnya kata "kopok". Kata itu termasuk ke dalam kecap sebab memiliki arti yaitu kasakit dina ceuli anu kaluar jiga nanah. Kata "kopok" merupakan salah satu kata yang ditemukan dalam penelitian ini.

Lokasi dalam penelitian ini yaitu semua desa yang berada di Kecamatan Karangnunggal. Jumlah desa seluruhnya ada 14 desa yang terdiri dari Desa Cidadap, Desa Kujang, Desa Sarimukti, Desa Ciawi, Desa Cikapinis, Desa Cikupa, Desa Karangnunggal, Desa Karangmekar, Desa Cibatuireng, Desa Cibatu, Desa Sukawangun, Desa Cintawangi, Desa Cikukulu, jeung Desa Sarimanggu.

Dari hasil penelitian, ditemukan 486 kata bahasa Sunda dialek Tasikmalaya di Kecamatan Karangnunggal dari 417 kata bahasa Sunda lulugu yang dibandingkan.

Ciri Pembeda Bahasa Sunda Dialek Tasikmalaya dan Bahasa Sunda Lulugu Dari 486 kata bahasa Sunda dialek Tasikmalaya di Kecamatan Karangnunggal, dianalisis berdasarkan 
ciri pembeda dialek menurut Guiraud (dalam Zulaeha, 2010, hal. 31) yaitu pembeda fonetik, pembeda morgologis, pembeda semantic, pembeda onomasiologis, dan pembeda semasiologis.

\section{Pembeda Fonétik}

Dari hasil analisis data, terdapat 46 kata basa Sunda dialek Tasikmalaya di Kecamatan Karangnunggal yang termasuk dalam pembeda fonetik. Dari 46 kata yang termasuk pembeda fonetik, ditemukan 24 kata yang beda karena hilangnya fonem; contohnya hilang foném $d$ : céndol $\rightarrow$ cénol , 20 kata yang patukeur foném; contohnya patukeur foném $/ \mathrm{j} / \rightarrow / \mathrm{y} /$ : rinjing $\rightarrow$ rinying, dan ditemukan 2 kata yang termasuk dalam tukeur posisi foném; contohnya tukeur posisifoném /l/ $\rightarrow$ /d/ : kelud $\rightarrow$ kedul.

\section{Pembeda Morfologis}

Pembeda morfologis yang ditemukan dari hasil analisis data yaitu ada 7 kata. Dari 7 kata tersebut, ada tiga kata yang bertambah rarangkén tukang an contohnya congé $\rightarrow$ congéan, satu kata yang bertambah rarangkén tukang -na yaitu nénéh $\rightarrow$ nénéhna, satu kata yang bertambah rarangkén hareup $k a$ - yaitu nénéh $\rightarrow$ kanénéh, dan dua kata yang bertambah rarangkén $N-$ di depan contohnya kelud $\rightarrow$ ngelud.

\section{Pembeda Semantik}

Dari hasil analisis data, dalam bahasa Sunda dialek Tasikmalaya di Kecamatan Karangnunggal ditemukan adanya pembeda semantik yang terdiri dari homonimi dan sinonimi.

\section{Homonimi}

Perbedaan bahasa Sunda dialek Tasikmalaya di Kecamatan Karangnunggal dengan bahasa Sunda lulugu yaitu adanya perbedaan arti dalam bentuk kata yang sama. Dari hasil analisis data, terdapat enam kata yang termasuk ke dalam perbedaan homonimi. Contohnya, kata céntong dalam bahasa Sunda dialek Tasikmalaya di Kecamatan Karangnunggal artinya séndok gedé paranti nyiuk angeun tina panci, sedangkan kata céntong dalam bahasa Sunda lulugu artinya séndok paranti nyiuk sangu.

\section{Sinonimi}

Perbedaan bahasa Sunda dialek Tasikmalaya di Kecamatan Karangnunggal dengan bahasa Sunda lulugu yaitu adanya persamaan arti dalam bentuk kata yang berbeda. Dari hasil analisis data, ditemukan 411 kata yang termasuk dalam perbedaan sinonimi. Contohnya seperti kata babantal dalam bahasa Sunda dialek Tasikmalaya di Kecamatan Karangnunggal dengan kata katimus dalam bahasa Sunda lulugu memepunyai arti yang sama yaitu papais sampeu anu di jerona make gula tur diasakanna diseupan.

\section{Onomasiologis}

Setiap daerah, pasti memiliki bahasa khasnya sendiri yang disebut dialek. Walaupun bahasa itu termasuk dalam dialek, tetapi memeliki konsep atau dasar yang hamper sama dengan bahasa lulugu.

Begitupun di Kabupaten Tasikmalaya Kecamatan Karangnunggal, terdapat dua puluh dua kata yang termasuk dalam pembeda onomasiologis. Seperti contohnya kata babareuhan memiliki konsep yang hamper sama dengan kata busung dalam bahasa lulugu. Kata babareuhan asalnya dari kata bareuh direduplikasi dwipurwa binarung rarangkén tukang -an artinya sama dengan kata busung yaitu bareuhna beuteung lantaran kasakit di jero beuteung.

Contoh lain yaitu kata bobokoh berasal dari kata boboko $+-h$ yang sama artinya dengan wadah sééng dalam bahasa lulugu. Zaman dahulu, jika mengangkat 
sééng dari hawu suka disimpan di atas boboko yang diisi abu.

\section{Pembeda Semasiologis}

Sebaliknya dari onomasiologis, semasiologis yaitu suatu kata mempunyai beberapa konsep atau makna. Dalam bahasa Sunda dialek tasikmalaya di Kecamatan Karangnunggal, terdapat lima belas kata yang termasuk dalam pembeda semasiologis. Contohnya, kata pipir mempunyai tiga arti yaitu (1) buruan, (2) panyawéran, jeung (3) sisi, kata titit mempunyai tiga arti yaitu (1) anak éntog, (2) anak hayam, jeung (3) anak meri, kata cemé mempunyai dua arti yaitu (1) anak munding dan (2) anak sapi, kata béwér mempunyai dua arti yaitu (1) épés méér dan (2) ogo, serta kata ené mempunyai dua arti yaitu (1) sesebutan keur awéwé kolot dan (2) nini.

\section{Bentuk Kata Bahasa Sunda Dialek Tasikmalaya di Kecamatan Karangnunggal}

Bentuk atau tata kata merupakan wujud kata dilihat dari morfem yang menjadi unsur pembentuknya. Begitu pula bentuk kata bahasa Sunda dialek Tasikmalaya di Kecamatan Karangnunggal bisa dilihat dari morfem yang menjadi unsur pembentuknya. Berdasarkan hasil analisis data, bentuk kata bahasa Sunda dialek Tasikmalaya di Kecamatan Karangnunggal terdiri dari kecap salancar dan kecap jembar. Dalam kecap jembar terdiri dari kecap rundayan, kecap rajékan, kecap kantétan, dan kecap wancahan.

\section{Kecap Salancar}

Kecap salancar yaitu kata yang dibentuk oleh satu morfem bebas, yang disebut leksem salancar, tanpa adanya perupahan apapun (Sudaryat, dkk. 2013. Hal. 59). Kecap salancar dalam bahasa Sunda dialek Tasikmalaya di Kecamatan Karangnunggal mengacu pada kata bahasa Sunda dialek yang dibentuk oleh satu morfem bebas tanpa ada perubahan apapun. Dari hasil analisis data, terdapat 324 kata yang termasuk dalam kecap salancar. Contohnya, kata angel, béca, bagenyél, bengkok, béwér, jst.

Berdasarkan pola suku katanya, ditemukan beberapa pola suku kata dalam kecap salancar bahasa Sunda dialek Tasikmalaya yaitu kecap salancar saengang, kecap salancar dua engang, kecap salancar tilu engang, dan kecap salancar opat engang. Pola itu merupakan vokal (V) atau kombinasi vokal (V) konsonan (K).

Dari hasil analisis data, kecap salancar yang paling banyak ditemukan ada pada pola kecap salancar dua engang, sedangkan yang paling sedikit ada pada pola kecap salancar saengang. Dalam kecap salancar saengang ada dua pola, yang paling banyak ada pada pola KVK, contohnya kata jol. Dalam kecap salancar dua engang ada 12 pola, dan kata yang paling banyak ada pada pola KV-KVK, contohnya kata camat, célot, gojéh, jangél, dan kétos . dalam kecap salancar tilu engang ada 13 pola, dan kata yang paling banyak ada pada pola KV-KV$\mathrm{KVK}$, contohnya kata celetok, gonokeun, jenolan, kabelih, dan soronoy. Dalam kecap salancar opat engang ada 7 pola, kata yang paling banyak ada pada pola KV-KV-KV-KVK, contohnya kata bébélécék, kekelekey, kilikiben, parupuyan, dan seseledek.

\section{Kecap Jembar}

Kecap jembar dalam bahasa Sunda dialek Tasikmalaya di Kecamatan Karangnunggal mengacu pada kata bahasa Sunda dialek yang dibentuk oleh dua morfem atau lebih. Dari hasil analisis data, ditemukan 137 kata yang termasuk dalam kecap jembar. Dari 137 kata itu, ada yang termasuk dalam kecap rundayan, kecap rajékan, kecap kantétan, dan kecap wancahan.

\section{Kecap Rundayan}

Kecap rundayan yaitu kata yang dibentuk dengan cara menambahkan 
imbuhan (afiks) pada bentuk dasarnya (Sudaryat, dkk. 2013, hal. 59). Kecap rundayan bahasa Sunda dialek Tasikmalaya di Kecamatan Karangnunggal mengacu pada kata bahasa Sunda dialek diberi imbuhan, baik itu imbuhan depan (prefiksasi), imbuhan belakang (sufiksasi), maupun (konfiksasi). Dari hasil analisis data, dalam bahasa Sunda dialek Tasikmalaya tedapat 54 kata yang termasuk kecap rundayan. Contohnya kata angkatan, ayakan, bageuran congéan, kabelik, kadeudeuh, $\mathrm{dsb}$. .

Dari hasil analisis data, dalam bahasa Sunda dialek Tasikmalaya ditemukan 11 pola kecap rundayan. Pertama, pola $D+$-an contohnya kata angkatan, ayakan, bageuran, dsb. Kedua pola $D+$-eun, contohnya kata barusuheun, cicingeun, dan gonongeun. Ketiga pola $D+-n a$, contohnya kata manéhna dan nénéhna. Keempat pola $k a$ $+-D$, contohnya kata kadeudeuh, kanénéh, kaselek, dsb. Kelima pola $k a+D$ + -an, contohnya kata kabuhulan dan kalamporan. keenam pola $N+D$, contohnya kata ngabata, ngarona, ngedul, nyamut, dsb. Ketujuh pola $p a+N+D$, yaitu kata panyiuk. Kedelapan pola $p a+$ $\mathrm{N}+\mathrm{D}+\quad$-an, contohnya kata pangangonan, panyitakan. Kesembilan pola pe+ $N+D$, yaitu kata penulis. Kesepuluh pola $s a+D$, yaitu kata sabudeur. Kesebelas pola sing $+D+-e u n$, yaitu kata singsireumeun. Kecap rundayan bahasa Sunda dialek Tasikmalaya paling banyak ditemukan pada pola $D+-a n$.

\section{Kecap Rajékan}

Kecap rajékan yaitu kata yang dibentuk dengan cara menyebut dua kali atau lebih bentuk dasarnya (Sudaryat, dkk. 2013, hal. 60). Kecap rajékan bahasa Sunda dialek Tasikmalaya di Kecamatan Karangnunggal mengacu pada kata bahasa Sunda dialek yang disebut dua kali, baik itu semuanya atau sebagian, binarung rarangkén ataupun tidak.
Dari hasil analisis data, terdapat 28 kata yang termasuk dalam kecap rajékan, contohnya kata ancam-éncém, babantal, cécémpéh, gagaruan, kekelekey, dsb.

Dari 28 kecap tersebut, ada 8 kata yang termasuk dalam kecap rajékan dwilingga, 5 kata termasuk dalam kecap rajékan dwi murni, contohnya kata uluulu, aclé-acléan, dsb; dan 3 kata termasuk kecap rajékan dwiréka yaitu kata ancaméncém, cuam-caém, dsb. Selain itu, ditemukan pula 20 kata yang termasuk kecap rajékan dwipurwa, contohnya kata babantal, bébécék, bébélécék, cécémpéh, gogodoh, dsb.

\section{Kecap Kantétan}

Kecap kantétan yaitu kata yang dibentuk dengan cara menggabungkan dua bentuk dasar, serta mengandung arti yang mandiri (Sudaryat, dkk. 2013, hal. 61). Kecap kantétan dalam bahasa Sunda dialek Tasikmalaya di Kecamatan Karangnunggal mengacu pada kata bahasa Sunda dialek Tasikmalaya yang memiliki arti baru setelah digabungkan dengan kata lain. Dari hasil analisis data, terdapat 46 kecap kantétan contohnya kata anak dulur, balas panganeun, bau héor, catang hawu, dudukuy cetok, dsb.

Dari hasil analisis data, ditemukan 9 pola dalam kecap kantétan. Pertama pola $\mathrm{KB}+\mathrm{KB}$, contohnya kata kanang emé, kanang japati, kanang sapi, dsb. Kedua pola $\mathrm{KB}+\mathrm{KS}$, contohnya kata bedog tekok, dudukuy cetok, sair bongkok. Ketiga pola $\mathrm{KB}+\mathrm{KP}$, contohnya kata kalingsir meuting, sawah garap, sawah kontrak, tempat wulu. Keempat pola KS + $\mathrm{KS}$, contohnya kata bau héor, bau héos. Kelima pola $\mathrm{KS}+\mathrm{KB}$, contohnya kata beurat birit, bodas ceuli, goréng adat, dsb. Keenam pola $\mathrm{KS}+\mathrm{KP}$ seperti kata gedé amek, gedé haok, dan nyeri kiih. Ketujuh pola $\mathrm{KP}+\mathrm{KB}$, contohnya kata pagawé désa. Kedelapan pola Kpan $+\mathrm{KS}$, seperti kata teu kaopan. Kesembilan pola Kpan + $\mathrm{KP}$, yaitu kata teu kagarap. Kecap kantétan dalam bahasa Sunda dialek 
Tasikmlaya ditemukan paling banyak pada pola $\mathrm{KB}+\mathrm{KB}$.

\section{Kecap Wancahan}

Kecap wancahan yaitu kata yang dibentuk dengan cara memendekkan kata atau kantétan kecap (Sudaryat, dkk. 2013, hal. 63). Kecap wancahan dalam bahasa Sunda dialek Tasikmalaya di Kecamatan Karangnunggal mengacu pada hasil meringkas kata bahasa Sunda dialek dengan cara mengambil fonem atau suku kata yang dianggap penting . Dari hasil analisis data, terdapat 9 kecap wancahan dalam bahasa Sunda dialek Tasikmalaya. Untuk lebih jelasnya, lihat data di bawah ini.

1. amang $\leftarrow$ wancahan tina mamang

2. apa $\leftarrow$ wancahan tina bapa

3. comro $\leftarrow$ wancahan tina oncom di jero

4. dé $\leftarrow$ wancahan tina dédé

5. éntong $\leftarrow$ wancahan tina céntong

6. né $\leftarrow$ wancahan tina néné

7. nyi $\leftarrow$ wancahan tina nyai

8. poldés $\leftarrow$ wancahan tina polisi Desa

9. siskamling $\leftarrow$ wancahan tina sistem kaamanan keliling.

Dari hasil analisis data, ditemukan empat macam kecap wancahan dalam bahasa Sunda dialek Tasikmalaya yaitu sirnamadya, sirnapurwa, kecap memet, dan tingkesan. Dari keempat macam tersebut, bahasa Sunda dialek Tasikmalaya paling banyak ditemukan pada kecap wancahan sirnapurwa.

\section{Dialektometri Bahasa Sunda Dialek Tasikmalaya di Kecamatan Karangnunggal}

Untuk menentukan seberapa jauh perbedaan dan persamaan bahasa Sunda dialek Tasikmalaya dengan bahasa lulugu, dihitung berdasarkan rumus:

$$
\frac{(s \times 100)}{n}=d \%
$$

Dari hasil penelitian, ditemukan:

$\mathrm{s}=231$

$\mathrm{n}=417$ $\mathrm{d}=55,39 \%$

Jadi, dapat disimpulkan bahwa bahasa Sunda dialek Tasikmalaya di Kecamatan Karangnunggal termasuk ke dalam klasifikasi beda dialek dengan tingkat perbedaan 55,39\%.

\section{KESIMPULAN}

Penelitian ini mempunyai tujuan untuk mengetahui kosa kata apa saja yang ada pada bahasa Sunda dialek Tasikmalaya di Kecamatan Karangnunggal. Selanjutnya, dianalisis ciri pembeda dialek dengan bahasa lulugu, bentuk kata, dan dialektometri.

Pertama, dari 417 kata bahasa Sunda lulugu yang diujikan ke informan, ditemukan 486 kata yang termasuk dalam bahasa Sunda dialek Tasikmalaya di Kacamatan Karangnunggal.

Kedua, bahasa Sunda dialek Tasikmalaya di Kecamatan Karangnunggal mempunyai perbedaan ciri dengan bahasa Sunda lulugu yaitu ada 46 kata yang memiliki pembeda fonetik, 7 kata yang memiliki pembeda morfologis, 6 kata yang memiliki pembeda homonimi, 411 kata yang memiliki pembeda sinonimi, 22 kata yang memiliki pembeda onomasiologis, dan 15 kata yang memiliki pembeda semasiologis.

Ketiga, berdasarkan bentuk katanya, dalam bahasa Sunda dialek Tasikmalaya di Kecamatan Karangnunggal terdapat 324 kecap salancar. Kecap salancar yang ditemukan ada pada empat pola engang, yaitu pola saengang, pola dua engang, pola tilu engang, dan pola opat engang. Dalam pola saengang ditemukan dua pola, bahasa Sunda dialek Tasikmalaya paling banyak ditemukan pada pola KVK. Dalam pola dua engang ditemukan 12 pola, bahasa Sunda dialek Tasikmalaya paling banyak ditemukan pada pola KV-KVK yaitu 117 kata. Dalam pola tilu engang terdapat 13 pola, bahasa Sunda dialek Tasikmalaya paling banyak terdapat pada pola KV-KV-KVK yaitu 40 kata. Dalam pola opat engang terdapat 7 pola, bahasa Sunda dialek Tasikmalaya paling banyak 
terdapat pada pola KV-KV-KV-KVK yaitu 6 kata. Selain kecap salancar, dalam bahasa Sunda dialek Tasikmalaya terdapat 137 kecap jembar. Dari 137 kecap jembar, ada yang termasuk kecap rundayan, kecap rajékan, kecap kantétan, dan kecap wancahan. Dalam kecap rundayan terdapat 11 pola, kata bahasa Sunda dialek Tasikmalaya yang paling banyak ada pada pola $D+$ an. Dalam kecap rajékan terdapat 28 kata, 8 kata termasuk dalam kecap rajékan dwilingga, 5 kata termasuk dalam kecap rajékan dwi murni dan 3 kata termasuk dalam kecap rajékan dwiréka, dan 20 kata termasuk dalam kecap rajékan dwipurwa. Dalam kecap kantétan terdapat 46 kata yang ada dalam 9 pola. Kecap kantétan dalam bahasa Sunda dialek Tasikmalaya paling banyak ditemukan pada pola $\mathrm{KB}+\mathrm{KB}$. Pada kecap wancahan terdapat 9 kata. Dari 9 kata itu, ada yang termasuk dalam sirnamadya, sirnapurwa, kecap memet, dan tingkesan.

Keempat, perbedaan bahasa Sunda

dialek Tasikmalaya di Kecamatan Karangnunggal dengan bahasa Sunda lulugu yaitu 55,39\%. Artinya, bahasa Sunda dialek Tasikmalaya di Kecamatan Karangnunggal termasuk dalam kalisifikasi beda dialek.

\section{DAPTAR PUSTAKA}

Arikunto, S. (2013). Prosedur Penelitian : Suatu Pendekatan Praktik. Edisi Revisi 2013. Jakarta: Rineka Cipta.

Ayatrohaedi. (1979). Dialektologi; Sebuah Pengantar. Jakarta: Pusat Pembinaan dan Pengembangan Bahasa Departemen Pendidikan dan Kebudayaan.

Azwar, S. (2012). Metode Penelitian. Yogyakarta: Pustaka Pelajar.
Chaer jeung Leonie Agustina. (2010). Sosiolonguistik; Perkenalan Awal. Jakarta: Rineka Cipta.

Marantika, E. (2016). Basa Sunda Dialék Parung Panjang nu Dipaké Ku Siswa SMP/SMA di Kacamatan Parung Panjang Kabupatén Bogor. [skripsi]. DPBD FPBS UPI.

Murdiani, A. M. (2013). Basa Sunda Dialek Bekasi di Kacamatan Setu pikeun Bahan Pangajran Maca di SMA. [skripsi]. DPBD FPBS UPI.

Sudaryat, spk. (2013). Tata Basa Sunda Kiwari. Bandung: Yrama Widya.

Sudjana, N. (2015). Tuntunan Penulisan Karya Ilmiah. Citakan ka-15 Februari 2015. Bandung: Sinar Buku Algensindo Bandung.

Sugiyono. (2012). 3 Bahasa Terpopuler di Indonesia . [online]. Diakses ti https://nasional.tempo.co/read/4352 18/3-bahasa-terpopuler-diindonesia.

Widyastuti, T. (2017). "Bahasa Sunda Dialek Pangandaran di Kecamatan Sidamulih". Lokabasa. 8, (1), 101110.

Yudibrata, K. spk. (1983). Geografi Dialék Sunda Kabupatén Tasikmalaya. Proyek Penelitian Bahasa dan Sastra Indonesia dan Daerah Jawa Barat. Departemen Pendidikan dan kebudayaan.

Zulaeha, I. (2010). Dialektologi; Dialek Geografi dan Dialek Sosial. Yogyakarta: Graha Ilmu.

\section{UCAPAN TERIMA KASIH}

Penulis mengucapkan banyak terima kasih kepada pihak yang telah membantu terselesaikannya penelitian ini. Mudah-mudahan penelitian ini bermanfaat untuk semua kalangan khususnya kalangan akademik. 